\title{
VOCACIÓN, RESPUESTA DEL HOMBRE AL DIOS QUE HABLA
}

José RAmÓn Romo SÁnchez-HEREdero ${ }^{1}$

DOI: https://doi.org/10.52039/seminarios.v57i199-200.358

\section{INTRODUCCIÓN}

Las narraciones bíblicas de la vocación constituyen lo que llamamos con propiedad un género literario bíblico bien diferenciado. Principalmente, porque mantienen una misma sucesión de elementos que subyacen a todas estas narraciones. Son como las líneas maestras del dibujo de un telar donde se van anudando personas, hechos, circunstancias...

$Y$ cuando nos acercamos a estos relatos de historias singulares queremos saber qué es lo que la Sagrada Escritura nos dice sobre la VOCACIÓN.

Una primera sorpresa nos llega. No sólo estos relatos nos hablan de la llamada. Nos hablan también de la respuesta; una respuesta a veces tan nimia que da vergüenza ajena, pero respuesta cierta del llamado o de la mujer llamada.

Ahí no paran las sorpresas, la Palabra es así siempre sorprendente para nuestros estrechos esquemas. Porque el centro de la narración lo constituye la MISIÓN que se encomienda. La llamada se hace con miras al encargo de una misión. La respuesta a la llamada se canaliza hacia la aceptación gozosa de esa misma misión.

Así que puestas estas bases de teología bíblica, con brevedad, nos va a resultar más provechoso y agradable adentrarnos en esta ponencia de las presentes JORNADAS: Vocación, respuesta del hombre al Dios que habla.

Por tanto, lo que aquí presento es una lectura vocacional del texto del Papa deteniéndome específicamente en el título de la ponencia.

La situación del presente texto nos ayudará a comprender mejor lo que nos proponemos.

El Sínodo sobre la Palabra de Dios viene precedido por el de la Eucaristía, ambos presididos por Benedicto XVI, y precede al próximo, en 2012, sobre la Nueva

1. Sacerdote Operario Diocesano. Párroco, Ntra. Sra. de la Purificación, Gamonal-Filial Inmaculada Concepción, El Casar de Talavera. Toledo. Este artículo es la ponencia presentada en las XXIII Jornadas de estudios teológicos: «Dimensión profética y evangelizadora: La palabra, fuerza y alimento del ministerio sacerdotal Dei Verbum, 21», en la reunión anual de los Seminarios Extremeños. Seminario mayor diocesano San Pedro Apóstol y María Inmaculada, Cáceres, 9-11 de marzo, 2011. 
Evangelización. Ofrece una reflexión sobre la Palabra e indicaciones pastorales para la liturgia, la catequesis, la pastoral vocacional, el diálogo interconfesional, etc. Por ello nos detenemos a modo de introducción en el texto postsinodal.

\section{Aproximación al texto de la Verbum Dominı}

La primera nota a resaltar es la relación del presente texto con la constitución conciliar Dei Verbum. En repetidas ocasiones hace referencia al texto del Concilio, más de 25 menciones, y establece unidad en los principios y concreción en sus indicaciones. $Y$ desde ahí dos son los puntos que quiero desarrollar en esta introducción del texto:

\subsection{La estructura vocacional de la VD}

Cuando me puse a leer con gusto y con tiempo la exhortación del Papa, me llamaron la atención varias connotaciones. La primera, la aparición frecuente de términos vocacionales. No sólo en alguna parte del texto más específica, sino como a modo de eje conductor a lo largo del todo el escrito. La segunda el tratamiento en este texto del sentido de la vocación (n. 22) ${ }^{2}$. La vocación es llamada y misión para la Alianza. Todas las vocaciones, es decir, el modo en el que se concreta la vocación de Dios en los convocados, tienen un mismo fin: la Alianza nueva y eterna en Jesucristo. La tercera, y esto me llamó aún más la atención, la estructura vocacional del texto que sigue el esquema de las narraciones bíblicas de la vocación que les he avanzado al principio. Y por último, la abundancia de términos vocacionales: vocación, llamada, misión, servicio, escucha, diálogo, etc.

Teniendo esto en cuenta, voy a presentar muy brevemente lo que he llamado la estructura vocacional de la VD.

a) La primera parte del texto, se titula VERBUM DEl. Es decir, nos ubica en el reino de la gracia, en la fuente de todo don. Es Dios y su Palabra quienes ponen en movimiento al ser, a toda criatura. Por eso establece su esquema en tres puntos:

-Dios habla

-La respuesta al Dios que habla

- La interpretación de la palabra de Dios

Aquí, en este reino de la gracia, se ubica el título de la ponencia, dejando asentado que la misma respuesta de la persona nace de la gracia de Dios.

2. A lo largo del texto aparecen una serie de citas de Verbum Domini (VDo). Algunas de esas citas están insertadas en el texto, como en el presente caso. Otras, al tener un significado especial y ser mas largas se anotarán a pie de página. 
b) La segunda parte del texto, se titula VERBUM IN ECCLESIA, y nos muestra el lugar que la Iglesia tiene en este dinamismo. Es la mediación de la gracia que Jesucristo ha querido dejar en la Iglesia en esta etapa de la salvación, hacia su segunda venida. Por ello, es la Iglesia quien,

-Acoge y celebra la Palabra

-Es la Palabra quien llena y plenifica la vida de la Iglesia

Y establece dos consecuencias para la pastoral y las describe con detalle: Palabra de Dios y pastoral; Palabra de Dios y vocaciones.

c) La tercera parte se titula VERBUM MUNDO. Queda claro que está hablando de la misión de la Palabra de Dios, de Jesús; por lo mismo, de la misión de la Iglesia; y, en consecuencia del término o fin de todo el dinamismo de la Palabra de Dios. Es Palabra para el mundo. Específicamente habla de misión, compromiso y testimonio.

- La misión de la Iglesia

-Compromiso en el mundo, con las culturas y el diálogo interreligioso

\subsection{El vocabulario vocacional que emplea la exhortación}

Denomino vocabulario vocacional a aquellas palabras y expresiones usadas en la teología de la vocación y de los ministerios que tienen su origen en la Sagrada Escritura, en el magisterio de la Iglesia y en la reflexión de los teólogos y pastores en la Iglesia.

Estas son: llamada, vocación, diálogo, respuesta, escucha, silencio, misión, envío, ministerio, servicio.

He ido recogiendo a lo largo del texto 257 palabras o expresiones breves vocacionales:

-Las expresiones que se refieren a la llamada de Dios, suman 95, el 37\%.

-Las que se refieren a respuesta: 103 , el $40 \%$.

-Las que se refieren a misión, envío, servicio: 59, el 23\%.

Algunas apreciaciones podemos hacer:

Está claro y acentuado el significado de la gracia en la vocación. Una llamada que el Papa ha querido subrayar como diálogo (36 veces). Por eso, mismo la respuesta aparece en términos similares (103 veces). Sin embargo, esta respuesta, antes que nada, nos dice el Papa es la escucha atenta, desde el silencio, en diálogo con el Dios que habla, que nos habla. Escucha y sus parientes aparece (80 veces en el texto con este sentido).

Por último, llama la atención la expresión familiaridad frecuente en este texto (en 11 ocasiones) y con la que el Papa hace hincapié en una relación especial con la Palabra de Dios, como veremos más adelante. 


\section{EL DIÁLOGO VOCACIONAL}

\subsection{Dios habla}

El Sínodo y el Papa con él ha querido decir, casi gritar: DIOS HABLA. Dios existe. Hablar de la existencia de Dios, de que Dios vive, de que Dios está de cara, antes que cualquier acercamiento o demostración de la razón e incluso de la razón iluminada por la fe, es Palabra que se deja oír, presente en la Sagrada Escritura, ante la cuál todos tenemos acceso, todos los que buscan, claro. Todos los que tienen sed. La Palabra encarnada es la epifanía viva de la existencia de Dios entre nosotros.

Es muy hermoso divisar esta verdad. Dios manifiesta su existencia por su Palabra encarnada. Una palabra audible, una Palabra inteligible que ha elegido nuestro mismo lenguaje para hacerse entender. Dios habla en nuestro lenguaje de carne y hueso y se llama Jesucristo. Jesucristo es la poesía de Dios, esa palabra trascendente, armoniosa, llena de belleza que nos señala más allá de nuestros límites el horizonte infinito de Dios, su corazón y su misericordia entrañable.

Una Palabra que está ahí, en la Iglesia, para anunciarla. No se deja limitar por ningún cerrojo. Se escapa siempre. Es libre y la Iglesia pone sus manos para derramar una y otra vez la semilla en los surcos de la historia humana.

\subsection{Dios llama}

La Verbum Domini recuerda el Concilio Vaticano II en la constitución Dei Verbum 2 que dice: «Dios invisible, movido de amor, habla a los hombres como amigos, trata con ellos para invitarlos y recibirlos en su compañía».

Un texto esencial que nos expone con claridad el dinamismo del Dios que se deja oír.

No sólo Dios habla y nos habla sino que nos trata como amigos y lo hace para invitarlos a su casa para recibirnos en su compañía.

Es la llamada de Dios. Su Palabra es llamada amorosa. Movido por su amor nos invita, nos convoca a su casa y a su mesa y nos recibe a la puerta envuelto en los fríos de la noche, en la soledad de los oteros.

Esta es la vocación de la que trata el texto. Es vocación al Amor de Dios. Ese destino alimenta como un ascua encendida y frágil nuestro deseo de Dios. Toda vocación es deseo de Dios.

Esa invitación y llamada del Verbo que está desde el principio junto a Dios y es Dios, nos revela al mismo Dios en el diálogo de amor de las Personas divinas y nos invita a participar en él ${ }^{3}$.

3. VDo, 6. 
Y como consecuencia, Dios se da a conocer en el diálogo que desea con nosotros. Esta es la novedad de la revelación bíblica. Dios habla y nos invita para entrar en diálogo.

Un diálogo que sólo podemos celebrar en Cristo 4 . Cuando Dios nos mira, contempla el rostro de su Hijo amado, en quien tiene toda complacencia. Porque la llamada a entrar en Dios es por la puerta de Cristo. Siendo Cristo.

«Estamos verdaderamente llamados por gracia a conformarnos con Cristo, el Hijo del Padre, y a ser transformados en Él» (VDo, 22).

Nuestra vocación es en Jesucristo. Él es nuestra vocación y en él está nuestra vocación.

\subsection{Respuesta del hombre}

\subsubsection{Nuestra respuesta también es gracia}

Y llegamos al núcleo de éste trabajo. La Verbum Domini trata el tema ampliamente en los nn. 22-28.

Era necesario ubicar el tema de la respuesta humana en el contexto de la presente Exhortación y, a la vez, en el dinamismo de la vocación. En ambos casos se resalta, como ha de ser, la gratuidad de todo el proceso de la vocación. Dios llama y la persona, hombre o mujer, responde y esa llamada-respuesta se realizan en el ambiente confiado del diálogo y por medio del diálogo. Diálogo de amigos que miran en la misma dirección. Diálogo gratuito, porque aún la misma respuesta está urgida y urdida por la gracia de Dios.

En este sentido, es necesario aclarar al exponer el tema que la vocación no tiene dos dinamismos polarizados: uno el de la gracia y otro el de la persona. Todo es gracia y ésta respeta la autonomía del que llama y la autonomía del que responde. Pero conviene no adornar con méritos y esfuerzos, con voluntarismos ineficaces o con disimulado orgullo espiritual la realidad de la vocación. No es la persona con sus méritos y esfuerzos la que conquista la vocación. La respuesta humana como veremos está en el ámbito de la gracia y se concreta en la confianza humilde y en el agradecimiento gozoso. El ser humano no con-

4. Leer e intentar profundizar estos textos valiosos del Papa en la presente exhortación ha provocado la memoria de los párrafos sobre el diálogo de la Iglesia con el mundo actual de Pablo VI en la Ecclesiam suam. Valga en este lugar esta breve mención: «He aquí, Venerables Hermanos, el origen trascendente del diálogo. Este origen está en la intención misma de Dios. La religión, por su naturaleza, es una relación entre Dios y el hombre. La oración expresa con diálogo esta relación. La revelación, es decir, la relación sobrenatural instaurada con la humanidad por iniciativa de Dios mismo, puede ser representada en un diálogo en el cual el Verbo de Dios se expresa en la Encarnación y, por lo tanto, en el Evangelio. El coloquio paterno y santo, interrumpido entre Dios y el hombre a causa del pecado original, ha sido maravillosamente reanudado en el curso de la historia. La historia de la salvación narra precisamente este largo y variado diálogo que nace de Dios y teje con el hombre una admirable y múltiple conversación», cf. Ecclesiam Suam, 28. 
quista la vocación. Siempre, siempre, Dios la regala, cuando quiere, como quiere y a quien quiere, sin excepciones.

El misterio de la Alianza expresa esta relación entre Dios que llama con su Palabra y el hombre que responde, siendo claramente consciente de que no se trata de un encuentro entre dos que están al mismo nivel; lo que llamamos Antigua y Nueva Alianza no es un acuerdo entre dos partes iguales, sino puro don de Dios. Mediante este don de su amor, supera toda distancia y nos convierte en sus 'partners', llevando a cabo así el misterio nupcial de amor entre Cristo y la Iglesia. En esta visión, cada hombre se presenta como el destinatario de la Palabra, interpelado y llamado a entrar en este diálogo de amor mediante su respuesta libre. Dios nos ha hecho capaces de escuchar y responder a la Palabra divina ${ }^{5}$.

\subsubsection{Dios escucha al ser humano y responde a sus interrogantes}

La respuesta del hombre es antes que nada respuesta de Dios. Cuando intentamos responder al Señor en sus continuas llamadas, nos quedamos esperando siempre sus respuestas a nuestros interrogantes (cf. Sal 76). Aquellos que perduran con la existencia humana uncidos a su devenir. Aquellos interrogantes que suscitan la realidad de nuestra historia y del mundo. Aquellos, más personales, en los que se libra la lucha por la felicidad, que llamamos vocacionales. Muchas preguntas a Dios. Y Dios no se cansa de nuestras preguntas. Sólo espera que en alguna ocasión nuestras acuciantes preguntas den tiempo a que Él responda.

El diálogo con Dios no acalla nuestras preguntas, nuestras inquietudes, más bien las suscita y las encauza, las purifica. Quien se acerca a la Palabra lo primero que encuentra son preguntas.

Por eso en el diálogo con Dios, nos comprendemos a nosotros mismos (VDo 23). Buen apunte para integrar teología y psicología.

\subsubsection{Nuestra respuesta mediante las palabras de Dios}

En el diálogo, coloquio 6 dice el Papa, él mismo nos enseña a hablar. Como un padre que va sembrando en los labios de sus hijos las palabras esenciales: las que muestran que estamos vivos, y que pertenecemos a esta u otra familia, las palabras del amor y de la tristeza, las de la pobreza y las de la pureza, las de la adoración. El Papa señala los salmos como palabra privilegiada para ha-

5. Cf. VDo, 22. Los subrayados que aparecen en la cita son del autor del presente trabajo. Se ofrecen como muestra de la profunda comprensión del Papa de los términos vocacionales en la Exhortación con motivo del Sínodo sobre la Palabra.

6. Coloquio tiene un sentido más familiar. El diálogo implica, al menos, una mínima estructura, el coloquio es más bien una conversación que nace de la relación, el interés, el acontecimiento. 
blar con Dios, mostrando la conformidad de este diálogo: Dios habla y nos enseña a hablarle, a responder a su invitación.

Así, la palabra que el hombre dirige a Dios se hace también Palabra de Dios, confirmando el carácter dialogal de toda la revelación cristiana, y toda la existencia del hombre se convierte en un diálogo con Dios que habla y escucha, que llama y mueve nuestra vida. La Palabra de Dios revela aquí que toda la existencia del hombre está bajo la llamada divina ${ }^{7}$.

Y subrayo la conclusión que el Papa toma de una de las proposiciones del Sínodo: ${ }^{8}$ TODA LA EXISTENCIA DEL HOMBRE ESTÁ BAJO LA LLAMADA DIVINA. Es evidente la intención de establecer la vocación y, por tanto, la respuesta, en el núcleo de la existencia humana. La vocación no es una llamada circunstancial, sino una palabra divina que compromete la vida.

\subsubsection{La respuesta es la fe}

En el número 25 el Papa establece el sentido de la respuesta: La respuesta propia del hombre al Dios que habla es la fe. Y la fe consiste en apertura. EI Papa define así la fe. La fe es la apertura del ser de cada persona. El ser humano tiene la llave del propio corazón y decide abrirse a aquella realidad que le trasciende. Decide llevar a cabo la misión que le desborda. Decide dar una respuesta de la cual no puede garantizar por sí mismo más que el hoy que está viviendo.

De nuevo el texto nos acerca al misterio del ser humano. Cerrados sobre sí mismos, el hombre y la mujer carecen de perspectiva, carecen de horizonte, carecen de futuro. Truncan una dimensión necesaria para su misma existencia, por su misma existencia. Y, poco a poco, se ven esclavos del pasado o del vacío propio. Han roto la luz y se encuentran ciegos ante su propio misterio. LA RESPUESTA ES LA FE.

El Otro me dirá quién soy yo y cuál el sentido de mis pasos y la misión que he realizar para plenificar este pequeño suspiro que es la existencia humana.

\subsubsection{Respuesta libre}

Ya en el número 22 el Papa dice que la respuesta del ser humano es respuesta libre. Y no puede ser de otra manera. Esta paradoja de la libertad y la necesidad de apertura, marca sin duda el dinamismo de la respuesta humana al Dios que habla.

Ya al inicio (n.9) el Papa nos ha hablado de la creación del hombre en libertad por ser imagen y semejanza del su Creador. Es el principio básico de la revelación

7. Cf. VDo, 24.

8. Prop. 75 
que mira al ser humano. Una libertad que encuentra su camino verdadero en Jesucristo: La libertad de Dios y la libertad del hombre se encuentran definitivamente en su carne crucificada, en un pacto indisoluble, válido para siempre (n.12).

Una libertad verdadera, no manipulada, puesto que el ser humano tiene la dramática posibilidad de sustraerse al diálogo que Dios le ofrece (n.26) como veremos más adelante.

\subsubsection{La respuesta al Dios que habla es la escucha}

A lo largo y ancho de este texto providencial del magisterio del Papa y Sinodal encontramos frecuentes alusiones a la escucha de la Palabra. Ya he anotado que la palabra escuchar y sus parientes, nominales o verbales suman 80 en el texto en todos los capítulos y apartados.

Podemos decir que es la clave del presente texto como respuesta humana y como respuesta vocacional. Ante el Dios que habla tenemos una posibilidad coherente: escuchar.

El Papa ha querido acentuar esta respuesta ante un mundo que camina entre ruidos (le cuesta despegarse de los medios de comunicación de masas, n. 66) y que ha perdido el sentido de la palabra. Volver a escuchar señala el gran reto que nos plantea la exhortación postsinodal.

En primer lugar, la escucha es sobre todo, hambre y sed de la Palabra que suscita el Espíritu Santo en nosotros. En segundo lugar, la escucha es ante todo silencio ante el Dios que habla.

Bastantes intervenciones de los Padres sinodales han insistido en el valor del silencio en relación con la Palabra de Dios y con su recepción en la vida de los fieles. En efecto, la palabra sólo puede ser pronunciada y oída en el silencio, exterior e interior. Nuestro tiempo no favorece el recogimiento, y se tiene a veces la impresión de que hay casi temor de alejarse de los instrumentos de comunicación de masa, aunque solo sea por un momento. Por eso se ha de educar al Pueblo de Dios en el valor del silencio. Redescubrir el puesto central de la Palabra de Dios en la vida de la Iglesia quiere decir también redescubrir el sentido del recogimiento y del sosiego interior. La gran tradición patrística nos enseña que los misterios de Cristo están unidos al silencio, y sólo en él la Palabra puede encontrar morada en nosotros, como ocurrió en María, mujer de la Palabra y del silencio inseparablemente ${ }^{9}$.

En tercer lugar, la escucha es comunión con cuantos se acercan a la Palabra de Dios, y experiencia de gozo precisamente por esa escucha en comunión.

Por gracia, hemos recibido el anuncio de que la vida eterna se ha manifestado, de modo que ahora reconocemos estar en comunión unos con otros, con quienes nos han precedido en el signo de la fe y con todos los que, diseminados por el

9. Cf. VDo, 66 . 
mundo, escuchan la Palabra, celebran la Eucaristía y dan testimonio de la caridad. La comunicación de este anuncio -nos recuerda el apóstol Juan- se nos ha dado «para que nuestra alegría sea completa» (1 Jn 1, 4). La Asamblea sinodal nos ha permitido experimentar también lo que dice el mensaje joánico: el anuncio de la Palabra crea comunión y es fuente de alegría ${ }^{10}$.

En cuarto lugar, la escucha impele al mensajero ${ }^{11}$. Es una actitud que el Papa con su intuición espiritual expone con fervor: el que escucha no puede por menos de convertirse en mensajero. La escucha es el camino de la fecundidad misionera. El que escucha se convierte en anunciador por la fuerza de la Palabra que ha llegado a su corazón.

No hay misionero si no hay orante. No hay misionero si no hay tiempo para escuchar la Palabra con tiempo y silencio interior.

\subsubsection{El pecado consiste en no escuchar}

El Papa ubica el núcleo oscuro del pecado justamente en no escuchar. Esa es la dureza de corazón, la cerviz dura que no se inclina.

Con mucha frecuencia, tanto en el Antiguo como en el Nuevo Testamento, encontramos la descripción del pecado como un no prestar oído a la Palabra, como ruptura de la Alianza y, por tanto, como la cerrazón frente a Dios que llama a la comunión con él, Jr 7, 22-28. En efecto, la Sagrada Escritura nos muestra que el pecado del hombre es esencialmente desobediencia y «no escuchar» ${ }^{12}$.

Obedecer significa escuchar desde abajo. Así estaba el hijo mayor junto al Padre. Sentado en un escaño a sus pies, escuchaba la voz del padre y salía corriendo a cumplir su mandado. Jesús nos ofrece en el Evangelio (Mt 21, 28-32) la parábola de los dos hijos a quien el padre manda a trabajar. Uno dice que sí, pero luego no va; el otro dice que no, pero luego va. Y Jesús concluye, como es de sentido, que el que cumple es el que va, de modo que la respuesta hablada no tiene importancia. Son respuestas de sentido vocacional: escuchar el envío y dejar todo para cumplir la misión.

\subsubsection{María «Mater Verbi Dei», «Mater fidei», «Mater laetitiae»}

El Sínodo sobre la Palabra puso de manifiesto el amor de la Iglesia a María, siempre Virgen, Madre de la Palabra de Dios. Son muy hermosos los números que el Papa dedica a exponer la doctrina (27, 28 y 124), y no sólo en ellos sino en las múltiples referencias que hace a la Virgen María.

10. Cf. VDo, 123.

11. VDo 124.

12. Cf. VDo 26. 
Los Padres sinodales han declarado que el objetivo fundamental de la XII Asamblea era renovar la fe de la Iglesia en la Palabra de Dios; por eso es necesario mirar allí donde la reciprocidad entre Palabra de Dios y fe se ha cumplido plenamente, o sea, en María Virgen, que con su sí a la Palabra de la Alianza y a su misión, cumple perfectamente la vocación divina de la humanidad.

Ella es la figura de la Iglesia a la escucha de la Palabra de Dios, que en ella se hace carne. María es también símbolo de la apertura a Dios y a los demás; escucha activa, que interioriza, asimila, y en la que la Palabra se convierte en forma de vida. La atención devota y amorosa a la figura de María, como modelo y arquetipo de la fe de la Iglesia, es de importancia capital para realizar también hoy un cambio concreto de paradigma en la relación de la Iglesia con la Palabra, tanto en la actitud de escucha orante como en la generosidad del compromiso en la misión y el anuncio ${ }^{13}$.

Así pues, todo lo que le sucedió a María puede sucedernos ahora a cualquiera de nosotros en la escucha de la Palabra y en la celebración de los sacramentos (n. 27-28).

Esta íntima relación entre la Palabra de Dios y la alegría se manifiesta claramente en la Madre de Dios. Recordemos las palabras de santa Isabel: 'Dichosa tú, que has creído, porque lo que te ha dicho el Señor se cumplirá' (Lc 1, 45). María es dichosa porque tiene fe, porque ha creído, y en esta fe ha acogido en el propio seno al Verbo de Dios para entregarlo al mundo. La alegría que recibe de la Palabra se puede extender ahora a todos los que, en la fe, se dejan transformar por la Palabra de Dios. El Evangelio de Lucas nos presenta en dos textos este misterio de escucha y de gozo. Jesús dice: 'Mi madre y mis hermanos son estos: los que escuchan la Palabra de Dios y la ponen por obra' $(8,21)$. Y, ante la exclamación de una mujer que entre la muchedumbre quiere exaltar el vientre que lo ha llevado y los pechos que lo han criado, Jesús muestra el secreto de la verdadera alegría: 'Dichosos los que escuchan la Palabra de Dios y la cumplen' $(11,28)$. Jesús muestra la verdadera grandeza de María, abriendo así también para todos nosotros la posibilidad de esa bienaventuranza que nace de la Palabra acogida y puesta en práctica ${ }^{14}$.

\section{La pastoral de las vocaciones a la luz de la Verbum DominI}

\subsection{Palabra de Dios e Iglesia}

La Iglesia existe para recibir la Palabra, dejarse transformar por ella con la fuerza del Espíritu y anunciar a todos los pueblos el Verbo encarnado.

Así nace la Iglesia como pueblo nuevo. Los que creen, los que viven de la escucha han nacido de Dios, participan de la vida divina. Se perfila aquí «el rostro de la Iglesia, como realidad definida por la acogida del Verbo de Dios que, haciéndose carne, ha venido a poner 'su morada entre nosotros' (Jn 1, 14)» (n. 50).

13. Prop. 55.

14. VDo, 124. 
Pero esta Iglesia que acoge al Verbo no puede ser comprendida como un acontecimiento del pasado. La relación entre el Verbo y la Iglesia es una relación vital, es decir, del hoy de todo hombre y toda mujer que reciben la llamada en el hoy. Dios no es el pasado.

\subsection{Palabra de Dios y vocaciones}

El n. 77 de la exhortación se convertirá en un texto ampliamente repetido y estudiado en la teología y en la pastoral de la vocación. El Papa avanza una dimensión objetiva y profunda. Es la Palabra de Dios la que llama, la que deja oír la voz del Señor en el corazón de quienes se acercan a esa llamada.

Es más, el trato con la Palabra y el conocimiento de la Palabra será lo que nos dará claridad a nos hará tomar opciones concretas de vida vocacional. Tú no eres quien llama, eres la mediación para que los jóvenes, los que buscan sentido encuentren la Palabra. En su contacto y por su voz muchos encontrarán la llamada que ha de despertar sus oídos sordos. Con claridad meridiana el Papa dice:

El Sínodo, al destacar la exigencia intrínseca de la fe de profundizar la relación con Cristo, Palabra de Dios entre nosotros, ha querido poner de relieve el hecho de que esta Palabra llama a cada uno personalmente, mostrando así que la vida misma es vocación en relación con Dios. Esto quiere decir que, cuanto más ahondemos en nuestra relación personal con el Señor Jesús, tanto más nos daremos cuenta de que Él nos llama a la santidad mediante opciones definitivas, con las cuales nuestra vida corresponde a su amor, asumiendo tareas y ministerios para edificar la Iglesia ${ }^{15}$.

A continuación el texto de la exhortación se detiene en perfilar la relación de la Palabra con cada una de las grandes ramas vocacionales del tronco común de la Iglesia: ministerio ordenado, vida consagrada y vocación laical.

\subsubsection{Ministerio ordenado. Seminaristas ${ }^{16}$}

El Papa subraya en esta reflexión sobre la respuesta al Dios que habla, el carácter del oyente de la Palabra. Una escucha que no es exterior sino interior. Al sacerdote ( $n$. 78) y al seminarista, el trato con la Palabra le han de llevar a dejarse proteger y alimentar, a vivir dentro de la Palabra:

Los candidatos al sacerdocio deben aprender a amar la Palabra de Dios. Por tanto, la Escritura ha de ser el alma de su formación teológica, subrayando la indispensable circularidad entre exégesis, teología, espiritualidad y misión ${ }^{18}$.

15. VDo 77.

16. Como queda dicho la ponencia se inscribía en las Jornadas de Teología que organizan los seminarios extremeños cada año. Por eso se resalta especialmente lo que la exhortación papal dice sobre el ministerio ordenado y la vida de los seminaristas.

17. VDo 82, que se basa en Prop. 32. 
Y sigue diciendo,

... la fe, como respuesta a la Palabra, se convierta en el nuevo criterio de juicio y apreciación de los hombres y las cosas, de los acontecimientos y los problemas ${ }^{18}$.

\subsubsection{Vida consagrada}

En el n. 83 que dedica a la Vida consagrada encontramos la misma coherencia de todo el texto. La Vida Consagrada nace de la escucha a la Palabra. Ha de alimentarse continuamente de ella y debe ser un testimonio para nuestro mundo de silencio y contemplación.

\subsubsection{Vida laical. Matrimonio}

Así mismo ocurre con respecto a la vocación laical, al matrimonio y la familia. El Papa se detiene especialmente en este apartado en el que encontramos las indicaciones vocacionales que venimos comentando.

Subraya el discernimiento a la luz de la Palabra para aquellos que tienen su vocación, insertos en las realidades temporales. Y señala el Papa cuál es la misión a la que deben responder los laicos en el matrimonio y la familia.

Los esposos han de acoger la Palabra de Dios como el mejor medio para las dificultades de la vida conyugal y familiar. Los padres son los primeros anunciadores de la fe a sus hijos. La comunidad eclesial debe fomentar la lectura de la Palabra y la formación, incluso formando pequeñas comunidades familiares donde se reciba con gozo y fortaleza la Palabra del Señor.

\subsection{Palabra en el mundo}

El texto de la exhortación nos presenta esta tercera parte vocacional ampliamente: del número 90 al 120. Es de nuevo en los textos del magisterio de la Iglesia un proyecto de pastoral, unos nuevos criterios de acción pastoral que deben iluminar los planes de las conferencias episcopales, de las diócesis, congregaciones y diferentes áreas de la Evangelización.

Para el estudio que nos ocupa, esta parte es la concreción de la respuesta vocacional; sin ella ésta quedaría en el aire, sin cuerpo. Voy a señalar someramente aquellos aspectos que me parecen relevantes para nuestro estudio.

Cuatro son los apartados que el Papa marca en la dimensión misionera de la Iglesia: la fundamentación de la Iglesia siguiendo la EN de Pablo VI; el anuncio de la Palabra como compromiso en el mundo; La Palabra en el arte y las culturas; y la Palabra en el diálogo interreligioso.

18. VDo 82, que se basa en PDV 47. 
La segunda parte marca de manera especial los objetivos de la misión de la Iglesia que se deja iluminar y sondear por la Palabra. Y lo hace según las siguientes prioridades:

-El anuncio a los humildes hermanos: pobres, emigrantes, los que sufren

-Justicia, reconciliación, paz y caridad efectiva

-Anuncio a los jóvenes

-Anuncio de la Palabra y salvaguarda de la Creación

Y el escrito destaca dos dimensiones que el Papa y el Sínodo desean que la Iglesia toda tenga muy en cuenta: El diálogo con el arte y las culturas y el diálogo interreligioso. En este sentido, el Papa ha convocado un nuevo encuentro interreligioso en el XXV aniversario del convocado por Juan Pablo II en Asís para el próximo octubre.

Recojo aquí tres citas de esta tercera parte que señalan con matices claros la fuerza que el Papa pone a la misión de la Iglesia en este momento histórico.

Su Palabra no sólo nos concierne como destinatarios de la revelación divina, sino también como sus anunciadores. Él, el enviado del Padre para cumplir su voluntad (cf. Jn 5, 36-38; 6, 38-40; 7, 16-18), nos atrae hacia sí y nos hace partícipes de su vida y misión. El Espíritu del Resucitado capacita así nuestra vida para el anuncio eficaz de la Palabra en todo el mundo ${ }^{19}$.

La Iglesia ha de ir hacia todos con la fuerza del Espíritu (cf. 1 Co 2, 5), y seguir defendiendo proféticamente el derecho y la libertad de las personas de escuchar la Palabra de Dios, buscando los medios más eficaces para proclamarla, incluso con riesgo de sufrir persecución ${ }^{20}$.

Nuestra responsabilidad no se limita a sugerir al mundo valores compartidos; hace falta que se llegue al anuncio explícito de la Palabra de Dios. Sólo así seremos fieles al mandato de Cristo $^{21}$.

\section{Conclusión: FAmiliaridad con la PalABra}

El Papa utiliza frecuentemente en el texto la palabra familiaridad para definir la relación que el cristiano ha de tener con la Palabra de Dios. Es como un grado de intimidad, es como una estancia especial.

Una figura concorde con el ser hijos e hijas de Dios que provoca la Palabra. Se trata de un trato familiar. El mismo Papa así lo define como trato confiado y asiduo 22 .

Pero a la vez familiaridad nos recuerda el trato sencillo y sin recelos de una amistad fiel. Hasta el punto que hay libertad para mostrarse como cada uno es

19. VDo 91.

20. VDo 95.

21. VDo 98.

22. Cf. VDo 59 y 104. 
sin represiones o violencias. El Papa hablando de la familiaridad de la Virgen María con la Palabra de Dios, dice que Ella entra y sale con naturalidad como de la propia casa (28).

Ahora bien ese trato confiado sólo se consigue cuando hay una comprensión constante y profunda entre las personas. Y lo mismo con la Palabra de Dios. Esa desenvoltura y naturalidad sin forzar, sin manipular, sólo es posible cuando hay un conocimiento profundo y cordial de la Sagrada Escritura. Por ello el Papa hablará a los seminaristas de esa formación circular, un paso lleva al otro, en el que se inserta: exégesis, teología, espiritualidad y misión (82). Una descripción magnífica de los ejes trasversales de toda la formación al sacerdocio.

Para terminar, algunas pistas para concretar en la pastoral de las vocaciones estos criterios que nos da el Papa en la exhortación Verbum Domini. En el origen la pregunta adecuada: ¿Cómo crear esa familiaridad con la Palabra de Dios, a ejemplo de María, en aquellos niños, adolescentes y jóvenes que acuden a las parroquias y colegios?

1. Hacer presente la Biblia en las reuniones de catequesis de una manera respetuosa y digna.

2. Entrenar a los miembros de los grupos de la catequesis en el manejo de la Sagrada Escritura.

3. Poner en las manos de los jóvenes la Sagrada Escritura, facilitando su lectura y su comprensión.

4. Adaptar la lectio divina al ritmo de los jóvenes para que asimilen un método adecuado y profundo al acercarse a la Palabra de Dios.

5. Lectura asidua de la Palabra en los grupos de adolescentes y jóvenes, tanto a nivel individual como grupal.

6. Crear grupos de familias donde se celebre la Palabra de Dios, preparándola con cánticos y comentarios adecuados.

Termino con uno de los textos más bellos del Papa, el que se refiere a la Virgen María en el comentario que hace del Magníficat en Deus Charitas est, 251 y que cita en la Verbum Domini:

El Magníficat -un retrato de su alma, por decirlo así- está completamente tejido por los hilos tomados de la Sagrada Escritura, de la Palabra de Dios. Así se pone de relieve que la Palabra de Dios es verdaderamente su propia casa, de la cual sale y entra con toda naturalidad. Habla y piensa con la Palabra de Dios; la Palabra de Dios se convierte en palabra suya, y su palabra nace de la Palabra de Dios. Así se pone de manifiesto, además, que sus pensamientos están en sintonía con el pensamiento de Dios, que su querer es un querer con Dios. Al estar íntimamente penetrada por la Palabra de Dios, puede convertirse en madre de la Palabra encarnada. 